University of Nebraska - Lincoln

DigitalCommons@University of Nebraska - Lincoln

August 2004

\title{
Attachment and Depression Differentially Influence Nicotine Dependence Among Male and Female Undergraduates: A Preliminary Study
}

\author{
Dennis E. McChargue \\ University of Nebraska-Lincoln, dmcchargue2@unl.edu \\ Lee M. Cohen \\ Texas Tech University, Lubbock \\ Jessica W. Cook \\ University of Illinois-Chicago
}

Follow this and additional works at: https://digitalcommons.unl.edu/psychfacpub

Part of the Psychiatry and Psychology Commons

McChargue, Dennis E.; Cohen, Lee M.; and W. Cook, Jessica, "Attachment and Depression Differentially Influence Nicotine Dependence Among Male and Female Undergraduates: A Preliminary Study" (2004). Faculty Publications, Department of Psychology. 286.

https://digitalcommons.unl.edu/psychfacpub/286

This Article is brought to you for free and open access by the Psychology, Department of at DigitalCommons@University of Nebraska - Lincoln. It has been accepted for inclusion in Faculty Publications, Department of Psychology by an authorized administrator of DigitalCommons@University of Nebraska - Lincoln. 


\title{
Attachment and Depression Differentially Influence Nicotine Dependence Among Male and Female Undergraduates: A Preliminary Study
}

\author{
Dennis E. McChargue, PhD; Lee M. Cohen, PhD; Jessica W. Cook, MA
}

\begin{abstract}
The authors surveyed a convenience sample of 208 undergraduate students who reported that they smoked cigarettes. The primary hypothesis they tested was whether gender predicted nicotine dependence. They further tested whether depression and attachment would mediate or moderate this relationship. Hierarchical regression analyses with social desirability and smoking stage of change entered as covariates indicated that women exhibited greater nicotine dependence than men did $(\mathrm{p}<.01)$. Lower attachment scores fully mediated this relationship, whereas elevated depression scores moderated the relationship. These findings suggest that depression and the inability to bond with peers may promote nicotine dependence among young female students.
\end{abstract}

Key Words: attachment, cigarette smoking, depression, mood regulation, nicotine dependence

$\mathbf{A}$ lthough men and women smoke at comparable rates, evidence suggests that, on average, girls who begin smoking during their adolescent years continue smoking for 20 years, 4 years longer than their male counterparts. ${ }^{1}$ Moreover, women appear to be at increased risk of developing smoking-related illnesses compared with men with similar smoking histories. ${ }^{2-4}$ Given the persistence of smoking into adulthood and the health risks associated with continued smoking, health professionals' focus has increasingly turned to the identification of early vulnerability factors that contribute to the initiation and maintenance of smoking behavior among youth. ${ }^{5}$ One area in need of further exploration is the role that gender plays and how

Dennis E. McChargue is a research assistant professor in the Department of Psychology at the University of Illinois-Chicago and is affiliated with the Edward Hines, Jr VA Hospital, Hines, Illinois; Lee M. Cohen is an assistant professor in the Department of Psychology, Texas Tech University, Lubbock; and Jessica W. Cook is a graduate student in the Department of Psychology at the University of Illinois-Chicago. this variable may influence vulnerabilities that lead to nicotine dependence. In this study, we explore 2 possible vulnerability pathways (social and affective) that may differentially influence nicotine dependence levels among young male and female college students.

The social vulnerability pathway involves an individual's ability to form strong attachments to family and friends. Research that investigates the effect of attachment on smoking behavior indicates that familial and peer attachment influence cigarette smoking in different directions. Earlier studies document a negative relationship between familial attachment and cigarette smoking. ${ }^{6-8}$ Specifically, as familial attachment increases, adolescents are less likely to initiate smoking behavior. However, strong attachment to one's peers, particularly to peers that smoke, is positively related to cigarette smoking. ${ }^{9-11}$ Researchers such as DeCivita and Pagani,${ }^{12}$ for example, have suggested that the deterioration of familial relations motivates young people to seek other models (smoking friends) in their environment. Evidence suggests that women may be more influenced by the enhanced social affiliation of tobacco use rather than the pharmacological effects of cigarette smoking. ${ }^{13}$ Young female smokers' ability to become attached to others, therefore, may help explain why so many women become dependent on nicotine each year.

Most research that examines the relationship of attachment to cigarette smoking has been conducted with junior high and high school populations (eg, 7th through 12th graders) that typically represent intact family and peer groups. Although researchers have examined whether attachment factors influence smoking status, ${ }^{6-8}$ the effect of attachment on who may or may not become dependent on nicotine remains unknown. We designed this study to examine a sample of young men and women who had less contact with their families and were placed in a situation where 
peer attachment predominates their social relationships (eg, first-year college students).

Considering that the adjustment to college during the initial years is strongly associated with depression, particularly for young female students, ${ }^{14,15}$ we posited an affective vulnerability pathway. Specifically, it is feasible that depression may contribute to nicotine dependence in this subgroup. Earlier research in this area has indicated that nicotine dependence and depression are inherently connected among many individuals who smoke cigarettes. Cross-sectional studies show that symptoms of depression predict initiation, ${ }^{16-18}$ experimentation, ${ }^{18,19}$ and regular cigarette smoking. ${ }^{20,21}$ Given that women are twice as likely to experience major depression and that the onset of major depression coincides with the first years of college, ${ }^{22}$ the ability of nicotine to dispel depression effectively ${ }^{23,24}$ may act as a powerful smoking reinforcer for young first-year college women.

In general, individuals separated and independent from their usual family and peer groups may increase smoking rates to adjust to college life. It remains unclear, however, whether men or women are more likely to become dependent on nicotine during this stage in their lives. In this study, we examined whether gender predicted nicotine dependence levels in a convenience sample of college freshmen at Texas Tech University, Lubbock. To the extent that gender differentiated dependence levels, we further hypothesized that women would be more influenced by attachment and depression factors than their male counterparts would be. Specifically, we explored whether attachment and depression mediated (explained) or moderated (bolstered) the relationship between gender and nicotine dependence.

\section{METHOD}

\section{Participants}

Because we were studying whether gender and psychosocial factors influenced cigarette smoking behavior among college freshmen, we restricted participants to individuals who reported on a subject-pool mass survey conducted by the Department of Psychology at the beginning of each semester that they currently smoked cigarettes. The mass survey collects demographic information from all students enrolled in introductory psychology classes at Texas Tech and has been approved by the Institutional Review Board (IRB) as a means of recruiting participants for psychology experiments. We applied no exclusionary criteria to the cigarette smokers. Once we identified potential participants, we implemented a proactive telephone approach to recruit smokers into our present study. Data collected during the 2001 and 2002 spring and fall semesters showed that 3,926 students completed the mass survey. Of those students, 744 (19\%) reported they currently smoked cigarettes. A final sample of 208 students (56.7\% women, $42.8 \%$ men) agreed to participate. Identified smokers who did not participate in the study were students who were either not interested in participation or whom we were unable to reach by telephone.
On average, participants were aged 19 years $($ median $=$ 19); $86.1 \%$ identified themselves as White, $8.7 \%$ as Latino, $1.0 \%$ as African American, $1.0 \%$ as Native American, and $2 \%$ as "other." On average, participants reported they smoked lightly more that 5 days per week $(M=5.30, S D=2.12)$ and reported a moderate level of nicotine dependence $(M=5.79$, $S D=1.48) .{ }^{25}$ During the days when they reported smoking, $51.5 \%$ reported smoking 5 or fewer cigarettes, $17 \%$ reported smoking 6 to 10 cigarettes, $13.6 \%$ reported smoking 11 to 20 cigarettes, and $15 \%$ reported smoking 20 cigarettes or more.

\section{Measures}

\section{Cigarette Dependence}

We used the Fagerström Test for Nicotine Dependence $(\text { FTND })^{26}$ to assess cigarette dependence. The FTND measures symptoms of nicotine dependence on a 6-item scale, ranging from 0 to 10 , with higher scores indicative of greater dependence. The FTND exhibits moderate internal consistency (Cronbach's $\alpha=.64$ and .58 , respectively) and construct validity. ${ }^{27}$

\section{Depression}

To assess depressed mood, we used the depressiondejection subscale of the Profile of Mood States Questionnaire ${ }^{28}$ with the "right now" version to characterize the participant's mood at the time of testing. The depression/dejection subscale consists of 14 items on a 4-point Likert-type scale, with scores ranging from 0 and 56. Higher scores indicate higher levels of depression. The depression/dejection subscale has an internal consistency reliability of .90 and shows construct and predictive validity. ${ }^{28}$

\section{Attachment}

We used the Temperament and Character Inventory (TCI) ${ }^{29}$ to assess attachment. The attachment subscale of the TCI consists of 8 true/false items; it measures feelings of attachment to others. The attachment subscale has exhibited moderate internal consistency (Cronbach's $\alpha=.72$ ). ${ }^{30}$

\section{Social Desirability}

We assessed social desirability and used it to control for any demand characteristics associated with self-report and measured using the Social Acceptance vs Social Intolerance subscale of the TCI. ${ }^{29}$ The social acceptance subscale has been shown to exhibit moderate internal consistency (Cronbach's $\alpha=.64) .{ }^{30}$

\section{Stage of Change}

We administered the Contemplation Ladder $^{31}$ to assess smokers' readiness to quit. The 5 stages of readiness on the Contemplation Ladder correspond to the Stages of Change Mode $^{32}$ and include No thought of quitting; Think I need to consider quitting someday; Thinking I should quit but not quite ready; Starting to think about how to change my tobacco use pattern; and Taking action to quit (eg, cutting down, 
enrolling in a program). The Contemplation Ladder has been shown to have both concurrent and predictive validity. ${ }^{31}$

\section{Procedures}

Our study was approved and is in full compliance with the Texas Tech Institutional Review Board. After being screened by the mass survey and contacted by telephone, we asked the individuals who agreed to participate to sign up for 1 of the available 2-hour assessment sessions that were held twice weekly in an on-campus classroom. Group size for each session ranged from 4 to 20 students, and all participants were awarded course credit for their attendance. Assessment sessions were offered between 11:00 am and 4:00 pm to accommodate students' class schedules. Before being given a questionnaire packet, all participants provided informed consent. Questionnaire packets were counterbalanced in terms of the order in which each measure appeared in the form as a means of reducing order effects. Participants were told to turn in the packet to a research assistant present in the room once they had completed the questionnaire. No identifiable information appeared on the questionnaire packets.

\section{RESULTS}

\section{Analytic Plan}

We examined whether college-aged women or men would exhibit higher levels of nicotine dependence. In addition, we examined whether depression and attachment moderated or mediated the effect of gender and nicotine dependence. The mediation hypotheses would be confirmed if (1) a strong significant relationship existed between gender and nicotine dependence and (2) this relationship disappeared after considering the influence of attachment or depression on nicotine dependence. Such a finding would suggest that the influence of gender on nicotine dependence is brought about through issues with depression or attachment style. For example, gender would not be related to nicotine dependence unless the participant had attachment or depression issues. The moderation hypotheses posits that the effect of gender on nicotine dependence would be enhanced or strengthened only among college students who report high levels of either attachment or depression.

Analysis of variance (ANOVA) is the standard analytic approach for examining the influence of a dichotomous independent variable (eg, gender) on a continuous outcome variable (eg, nicotine dependence). ANOVA, however, does not provide tests of mediation. Therefore, we used hierarchical regression analysis, a more conservative approach when one uses a dichotomous predictor variable. Using hierarchical regression analysis to test study hypotheses allowed us to examine whether depression or attachment mediated gender's influence. We first checked descriptive statistics for all primary study variables and tested for differences between men and women (Table 1). One-way analysis of variance showed that women reported significantly higher nicotine dependence and higher motivation to quit smoking than did men (all $p s<$ .05). Conversely, women reported lower levels of attachment compared with men (all $p \mathrm{~s}<.05$ ). After considering the descriptive statistics, we calculated Pearson correlations to (1) rule out multicollinearity, (2) justify further tests of mediation, and (3) assess for potential covariates (Table 2).

Correlation analyses indicated that both stage of readiness to quit smoking and social desirability were significantly correlated with FTND score $(r=.32, p=.01, r=-.13, p=.03$, respectively). Thus, both stage of readiness to quit smoking and social desirability were statistically controlled in all analyses.

\section{Gender and Nicotine Dependence}

Hierarchical regression analysis indicated that gender predicted nicotine dependence after controlling for covariates, $R^{2}$ change $=.13, \beta=-.18, F(1, N=181)=6.41, p=$ .01 . These findings suggest that women are more likely than men to exhibit greater dependence on cigarettes.

\section{Does Attachment Mediate or Moderate the Effect of Gender on Nicotine Dependence?}

The preliminary correlations among gender, FTND, and attachment (Table 2) justified examination of whether attachment mediated the relationship between gender and nicotine dependence. Using the criteria set forth by Baron and Kenny, ${ }^{33}$ we examined whether (1) gender predicted

TABLE 1. Means and Standard Deviations Among Primary Variables $(N=208)$ in a Study of Nicotine Dependence

\begin{tabular}{|c|c|c|c|c|}
\hline \multirow[b]{2}{*}{ Variable } & \multicolumn{2}{|c|}{ Women } & \multicolumn{2}{|c|}{ Men } \\
\hline & $M$ & $S D$ & $M$ & $S D$ \\
\hline Nicotine dependence & 6.09 & 1.31 & 5.38 & $1.59 * *$ \\
\hline Attachment & 4.94 & 2.18 & 5.81 & $2.33 * *$ \\
\hline Depression & 8.17 & 11.77 & 8.38 & 11.51 \\
\hline Social desirability & 5.47 & 1.01 & 5.88 & 1.28 \\
\hline Stage of change & 7.05 & 2.65 & 6.17 & $3.09 *$ \\
\hline
\end{tabular}


TABLE 2. Intercorrelations Among Predictor, Criterion Variables, and Covariates $(N=208)$ in a Study of Nicotine Dependence

\begin{tabular}{|c|c|c|c|c|c|c|}
\hline Variable & 1 & 2 & 3 & 4 & 5 & 6 \\
\hline 1. Nicotine dependence & - & & & & & \\
\hline 2. Gender & $-.22 * *$ & - & & & & \\
\hline 3. Depression & .06 & -.01 & - & & & \\
\hline 4. Attachment & $-.29 * *$ & $.17 * *$ & $.19 * *$ & - & & \\
\hline 5. Stage of change & $.32 * *$ & $-.15^{*}$ & -.03 & $-.15^{*}$ & - & \\
\hline 6. Social desirability & $-.13^{*}$ & $.17 * *$ & -.07 & $.24 * *$ & $-.16^{*}$ & - \\
\hline
\end{tabular}

FTND, (2) gender predicted the mediator (attachment), and (3) with attachment and gender on the same regression step, only attachment significantly predicted nicotine dependence. Gender, then, predicted a significant portion of the observed variance in nicotine dependence.

Next, we conducted hierarchical regression analyses, controlling for covariates, which showed that gender significantly predicted level of attachment, $R^{2}$ change $=.03, \beta=$ $.17, F(1, N=185)=5.28, p=.02$. In other words, women were more likely than men to show low levels of attachment. When gender and attachment were entered onto the same step of the regression equation after controlling for covariates, only attachment, $\beta=-.22, p=.01$, and not gender, $b=-.14, p=.05$, predicted significant additional variance in FTND scores. The findings, therefore, suggest that attachment mediates the relationship between gender and level of nicotine dependence.

In further analyses, we also examined whether attachment moderated the influence of gender on nicotine dependence. Using the criteria set forth by Baron and Kenny, ${ }^{33}$ we examined whether the moderator variable (Gender $x$ Attachment) predicted significant variance in nicotine dependence after controlling for the main effects of gender and attachment. Hierarchical regression analysis revealed that after controlling for covariates, the moderator variable (Gender $\times$ Attachment) failed to predict a significant change in nicotine dependence, $R^{2}$ change $=.01, F(1, N=178)=$ $1.20, p=.25$.

\section{Does Depression Mediate or Moderate the Effect of Gender on Nicotine Dependence?}

As the data in Table 1 show, gender was not significantly associated with depression, indicating that depression would not mediate the effect of gender on nicotine dependence. ${ }^{33}$ When an unexpectedly weak relationship is identified, further assessment of moderation effects is justified. ${ }^{33}$ Hierarchical regression analysis showed that after controlling for covariates (gender and depressed mood), the moderator variable (Gender $\times$ Depressed Mood) predicted significant change in nicotine dependence, $R^{2}$ change $=.02, F(1, N=$ 177) $=4.05, p=.04$.
We then conducted simple effects tests with 2 separate regression analyses that examined the relationship between gender and nicotine dependence among (1) individuals with high levels of depressed mood and (2) among individuals with low levels of depressed mood. Findings indicated that gender predicted nicotine dependence among those with high levels of depressed mood, $F(1, N=95)=14.52, p=$ .00 , but not among those with low levels of depressed mood, $F(1, N=80)=.48, p=.30$. Thus, current depressed mood appears to interact with gender so that women are likely to exhibit elevated nicotine dependence only if they experience high levels of depression.

\section{COMMENT}

Our findings from the present study indicate that female smokers exhibit higher levels of nicotine dependence than do their male counterparts. Consistent with the study hypotheses, attachment mediated the relationship between gender and nicotine dependence; depression moderated this relationship. Lower levels of attachment mediated the gender-dependence relationship. Therefore, female smokers who did not perceive themselves as "connected" with their peer group were more dependent on nicotine. Moreover, female smokers with elevated depressive symptoms were also more dependent on nicotine.

Research examining the influence of attachment on cigarette smoking has shown that when the effect of family relations is controlled, peers play a major role in the initiation of smoking behavior. ${ }^{34,35}$ Consistent with this premise, we hypothesized that college freshmen removed from direct family influence (potentially for the first time in their lives), would look to friends to dictate their behaviors. Findings from the present study revealed that women who did not feel particularly connected to their peers were more likely to be dependent on nicotine. Previous research in this area has indicated that women are more influenced by nicotine's ability to increase social affiliation than with nicotine's pure pharmacological effects. ${ }^{13}$ However, these findings suggest that increased attachment to peers may not fuel the smoking behavior of first-year women students. 
Our findings revealing that women with elevated depression exhibited greater nicotine dependence may partially explain why women's low levels of attachment were so highly dependent. Although attachment was positively correlated with depression in the complete sample of male and female students, the moderation finding may suggest that, for women who rank low in attachment, the pharmacological properties associated with nicotine's ability to dispel depression may drive nicotine dependence levels. One may therefore speculate that difficulties in "connecting" with peers during the first years of college may produce depression $^{14,15}$ and that the combination of low attachment and depression lead young female smokers to become dependent on nicotine at a more rapid rate than would otherwise be expected.

We found no strong effects among the male students. A plausible explanation for the null finding among men is that detachment and depression are not issues that influence smoking among male college students. Compared with men, women are more likely to have difficulties in separating from their hometown family/friends ${ }^{36}$ and report greater levels of depression during late adolescence. ${ }^{37}$ These difficulties have also been shown to interfere with college adjustment. ${ }^{36,38}$ Such adjustment difficulties are presumed to foster smoking patterns as a coping mechanism that subsequently leads to early nicotine dependence. Smoking patterns among young male students, by contrast, may be more influenced by risk profiles, such as antisocial behavior, self-esteem issues, and lack of goal-oriented behavior, ${ }^{39}$ as well as sensation seeking and impulsivity. ${ }^{40}$

Results from the present study should be tempered and considered preliminary related to study limitations. First, because of the study's cross-sectional design, future research should develop prospective investigations to assess the causal inferences of these relationships. Second, the ability to generalize to other populations and settings was limited because we used a convenience sample of freshman introductory psychology students at 1 university in the Southwest. Perhaps students majoring in areas that do not require introductory psychology or who choose not to enroll in this course are different in some way. It is also possible that regional differences exist among students and that first-year students assessed in September are different from those assessed in February. Despite concerns regarding the ability to generalize to other populations, most study variables appear to represent large-scale samples. ${ }^{28,31,41,42}$ The only exception was the self-reported depression measure. This brief situation-specific measure produced scores 5 points lower than would represent a college sample. ${ }^{28} \mathrm{Nev}-$ ertheless, these lower depression levels may have resulted from the presumed antidepressant effects obtained from regular nicotine exposure. ${ }^{24}$

In conclusion, our findings suggest that college-aged men and women might be motivated to smoke and quickly develop dependence on nicotine for different reasons. We encourage college health professionals to examine individual-difference factors before addressing the smoking behav- iors of young adults. For example, it appears that difficulties in forming strong relationships with peers directly influence a young woman's progression toward becoming dependent on nicotine. This influence may be particularly salient for individuals who report symptoms of depression. To the extent that smoking reflects a maladaptive coping behavior, ${ }^{13,43}$ college health professionals may be able to improve smoking cessation rates among young women by helping them develop more adaptive ways to cope with feelings of detachment or depression as they matriculate into college life.

In addition, we recommend further empirical tests to strengthen the present findings. For example, the examination of whether differences in attachment patterns are observed in diverse situations (eg, when the individual was at home compared with when he or she enters college), especially given that attachment may be highly influenced by environmental and personal factors. Examining a depressive vulnerability pre- and postcollege entry may also help clarify the role of depression in the development of nicotine dependence among young female college students.

\section{ACKNOWLEDGMENT}

This research was partially supported by NIH grants 1 K08 DA00467 to Dr. McChargue and DA14144 to Jessica Cook.

\section{NOTE}

For comments and further information, please address correspondence to Dennis E. McChargue, PhD, Research Assistant Professor, Department of Psychology (M/C 285), University of Illinois at Chicago, 1007 West Harrison Street, Chicago, IL 60607 (email: dmccharg@uic.edu).

\section{REFERENCES}

1. Pierce JP, Gilpin E. How long will today's new adolescent smoker be addicted to cigarettes? Am J Public Health. 1996;86(2): 253-256.

2. Kure EH, Ryberg D, Hewer A, et al. P53 mutations in lung tumours: relationship to gender and lung DNA adduct levels. Carcinogenesis. 1996;17(10):2201-2205.

3. Prescott E, Osler M, Andersen PK, et al. Mortality in women and men in relation to smoking. Int J Epidemiol. 1998;27:27-32.

4. Silverman EK, Weiss ST, Drazen JM, et al. Gender-related differences in severe, early-onset chronic obstructive pulmonary disease. Am J Respir Crit Care Med. 2000;162:2152-2158.

5. Chassin L, Presson CC, Rose JS, Sherman SJ. The natural history of cigarette smoking from adolescence to adulthood: demographic predictors of continuity and change. Health Psychol. 1996;15(6):478-484.

6. Dornbusch SM, Erickson KG, Laird J, Wong CA. The relation of family and school attachment to adolescent deviance in diverse groups and communities. J Adolesc Res. 2001;16(4): 396-422.

7. Foshee V, Bauman KE. Parental attachment and adolescent cigarette smoking initiation. Journal of Adolescent Research. 1994;9(1):88-104.

8. Sokol-Katz J, Dunham R, Zimmerman R. Family structure versus parental attachment in controlling adolescent deviant behavior: a social control model. Adolescence. 1997;32(125): 199-215.

9. Ensminger ME, Brown CH, Kellam SG. Sex differences in antecedents of substance use among adolescents. J Soc Issues. $1982 ; 38(2): 25-42$. 
10. Krosnick JA, Judd CM Transitions in social influence at adolescence: who induces cigarette smoking? Dev Psychol. 1982;18 (3):359-368.

11. Marcos AC, Bahr SJ, Johnson RE. Test of a bonding/association theory of adolescent drug use. Soc Forces. 1986;65(1):135-161.

12. DeCivita M, Pagani L. Familial constraints on the initiation of cigarette smoking among adolescents: an elaboration of social bonding theory and differential association theory. Can J School Psychol. 1996;12(2):177-190.

13. Perkins KA. Sex differences in nicotine versus nonnicotine reinforcement as determinants of tobacco smoking. Exp Clin Psychopharmaco. 1996;4(2):166-177.

14. Lopez FG, Campbell VL, Watkins CE. Depression, psychological separation, and college adjustment: an investigation for sex differences. J Counsel Psychol. 1986;33:52-56.

15. Vivona JM. Parental attachment styles of late adolescents: qualities of attachment relationships and consequences for adjustment. J Counsel Psychol. 2000;47:316-329.

16. Brown RA, Lewinsohn PM, Seeley JR, Wagner EF. Cigarette smoking, major depression, and other psychiatric disorders among adolescents. J Am Acad Child Adolesc Psychiatry. 1996;35(12): 1602-1610.

17. Escobedo LG, Reddy M, Giovino GA. The relationship between depressive symptoms and cigarette smoking in US adolescents. Addiction. 1998;93(3):433-440.

18. Patton GC. Depression, anxiety, and smoking initiation: a prospective study over 3 years. Am J Public Health. 1998;88: 1518-1522.

19. Pesa JA, Cowdery JE, Wang MQ, Fu Q. Self-reported depressive feelings and cigarette smoking among Mexican-American adolescents. J Alcohol Drug Educ. 1997;43:63-75.

20. Patton GC, Hibber M, Roiser MJ, Carlin, JB, Caust J, Bowes G. Is smoking associated with depression and anxiety in teenagers? Am J Public Health. 1996;86(2):225-230.

21. Wang MQ, Fitzhugh EC, Westerfield RC, Eddy JM. Predicting smoking status by symptoms of depression for US adolescents. Psychol Rep. 1994;75(911-914).

22. Diagnostic and Statistical Manual of Mental Disorders. 4th ed. Washington, DC: American Psychiatric Association; 1994.

23. Salin-Pascual RJ, de la Fuente JR, Galicia-Polo L, Drucker-Colin R. Effects of transdermal nicotine on mood and sleep in nonsmoking major depressed patients. Psychopharmacology (Berl). Oct 1995;121(4):476-479.

24. Salin-Pascual RJ, Rosas M, Jimenez-Genchi A, Rivera-Meza BL, Delgado-Parra V. Antidepressant effect of transdermal nicotine patches in nonsmoking patients with major depression. J Clin Psychiatry. Sept 1996;57(9):387-389.

25. Fagerstrom KO, Heatherton TF, Kozlowski LT. Nicotine addiction and its assessment. Ear Nose Throat J. 1990;69(11): 763-765.

26. Heatherton TF, Kozlowski LT, Frecker RC, Fagerstrom KO. The Fagerstrom Test for Nicotine Dependence: a revision of the Fagerstrom Tolerance Questionnaire. Br J Addict. Sept 1991; 86(9):1119-1127.
27. Pomerleau CS, Carton SM, Lutzke ML, Flessland KA, Pomerleau OF. Reliability of the Fagerstrom Tolerance Questionnaire and the Fagerstrom Test for Nicotine Dependence. Addict Behav. 1994;19(1):33-39.

28. McNair DM, Lorr M, Droppleman LF. Manual for the Profile of Mood States (POMS). San Diego, CA: Educational and Industrial Testing Service; 1971.

29. Cloninger CR, Pryzbeck TR, Svrakic DM, Wetzel RD. The Temperament and Character Inventory (TCI). St. Louis, MO: Center for Psychobiology of Personality; 1994.

30. Cloninger CR, Svarkic DM, Przybeck TR. A psychobiological model of temperament and character. Arch Gel Psychiatry. 1993;50:975-990.

31. Biener L, Abrams DB. The Contemplation Ladder: validation of a measure of readiness to consider smoking cessation. Health Psychol. 1991;10(5):360-365.

32. Prochaska JO, DiClemente CC, Norcross JC. In search of how people change. applications to addictive behaviors. Am Psychol. 1992;47(9):1102-1114.

33. Baron RM, Kenny DA. The moderator-mediator variable distinction in social psychological research: conceptual, strategic, and statistical considerations. J Person Sol Psychol. 1986;51(6): 1173-1182.

34. Pawlak R, DeFronzo J. Social bonds, early trauma and smoking: evidence of the group specific relevance of control theory. $J$ Drug Educ. 1993;23(2):201-214.

35. Pilgrim C, Abbey A, Hendrickson P, Lorenz S. Implementation and impact of a family-based substance abuse prevention program in rural communities. J Prim Prevent. 1998;18(3): 341-360.

36. Lapsley DK, Rice KG, Shadid GE. Psychological separation and adjustment to college. J Counsel Psychol. 1989;36(3): 286-294.

37. Roberts JE, Gotlib IH. Lifetime episodes of dysphoria: gender, early childhood loss and personality. Br J Clin Psychol. 1997;36(2):195-208.

38. Street S, Kromrey JD. Differences in adjustment issues for male and female adolescents. Spec Serv Sch. 1994;8(2):143-154.

39. Soldz S, Cui X. A risk factor index predicting adolescent cigarette smoking: a 7-year longitudinal study. Psychol Addict Behav. 2001;15(1):33-41.

40. Baker JRY, John K. Moderating effect of gender on the relationship between sensation seeking-impulsivity and substance use in adolescents. J Child Adolesc Subst Abuse. 2002;12(1): 27-43.

41. Cloninger CR, Svrakic DM, Przybeck TR. The tridimensional personality questionnaire: US normative data. Psychol Rep. 1991;69:1047-1057.

42. Haddock CK, Lando H, Klesges RC, Talcott GW, Renaud EA. A study of the psychometric and predictive properties of the Fagerstroem Test for Nicotine Dependence in a population of young smokers. Nicotine Tob Res. 1999;1(1):59-66.

43. Carmody TP. Affect regulation, nicotine addiction, and smoking cessation. J Psychoactive Drugs. 1992;24(2):111-122. 